\title{
Pregnancy and oncologic outcomes of early stage low grade epithelial ovarian cancer after fertility sparing surgery: a retrospective study in one tertiary hospital of China
}

\author{
Jie Yin, Yongxue Wang, Ying Shan, Yan Li, Ying Jin and Lingya Pan*
}

\begin{abstract}
Objective: To detected both pregnancy and oncologic outcomes early stage low grade epithelial ovarian cancer (EOC) in one tertiary hospital of China.

Methods: Medical records of 40 EOC patients between January 2000 and December 2016 in Peking Union Medical College Hospital (PUMCH) were retrospectively reviewed.

Results: All patients were IA/IC low grade EOC patients. Mean age was 28 years (ranged from 18 to 44 years). Among them, 47.5\% had mucinous carcinoma, 22.5\% clear cell carcinoma, 20\% endometriod carcinoma, 10\% serous carcinoma. $40 \%$ of patients were operated under laparoscopy. $67.5 \%$ of patients received chemo-therapy after surgery. The median follow up time was 54 months (ranged from 25 to 201 months). The 2 year and 5 year of disease free survival were respectively 95 and $87.5 \%$. No death occurred. 27 patients (67.5\%) were single or contraceptive. 13 patients (32.5\%) tried to be pregnant, and 8 patients (61.5\%) have successfully conceived spontaneously, including 1 fetus loss, 1 fetus death in uterus, 1 fetal anomaly and 5 live births (2 premature births and 3 term births). There was no tumor recurrence happened during pregnancy.
\end{abstract}

Conclusions: Fertility sparing surgery was safe and pregnancy was encouraged to stage IA/IC low grade EOC patients.

Keywords: Epithelial ovarian cancer, Fertility preservation, Reproductive outcome, Oncologic outcomes

\section{Introduction}

Ovarian cancer is one of the most common malignancies of the female reproductive system in the world. The main pathological type is epithelial ovarian cancer (EOC). Around $10 \%$ of EOC is diagnosed in patients younger than 40 years. Preservation of fertility is very important for young patients of early EOC. The 5 years survival in stage I EOC ranges from 70 100\%, which depend on tumor biology and postsurgical treatments [1]. The primary treatment of ovarian cancer consists of

\footnotetext{
* Correspondence: panly@pumch.cn

Department of Obstetrics and Gynecology, Peking Union Medical College Hospital, Chinese Academy of Medical Science and Peking Union Medical College, Beijing, China
}

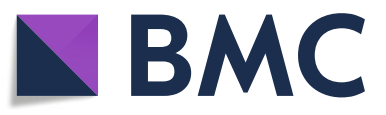

(c) The Author(s). 2019 Open Access This article is distributed under the terms of the Creative Commons Attribution 4.0 International License (http//creativecommons.org/licenses/by/4.0/) which permits unrestricted use, distribution, and reproduction in any medium, provided you give appropriate credit to the original author(s) and the source, provide a link to the Creative Commons license, and indicate if changes were made. The Creative Commons Public Domain Dedication waiver (http://creativecommons.org/publicdomain/zero/1.0/) applies to the data made available in this article, unless otherwise stated.

appropriate surgical staging and debulking surgery, followed in most patients by systemic chemotherapy. The complete surgical staging includes total abdominal hysterectomy (TAH) and bilateral salpingo-oophorectomy (BSO). However, for young patients who wish to preserve fertility, a unilateral salpingo-oophorectomy (USO) and comprehensive surgical staging may be adequate for select unilateral stage I tumors (FIGO stage IA and IC) [2-4]. For those with FIGO stage IB tumors who wish to maintain fertility, a BSO (preserving the uterus) and comprehensive surgical staging are needed. Careful surgical staging is critical for early EOC patients to rule out occult higher-stage disease, because nearly $30 \%$ of patients undergoing complete staging surgery are upstaged. 
Compared with conventional surgery, fertility sparing surgery (FSS) was not associated with increased risk of death in young women with stage I epithelial ovarian cancer [5]. According to many recent reports, the oncological outcomes of patients after fertility-sparing surgery are good, but their pregnancy outcomes are still unknown.

Since 2000, we performed fertility sparing surgery on low grade early stage epithelial ovarian cancer patients who wished to maintain fertility and could be followed up as required in Peking Union Medical College Hospital (PUMCH), Beijing, China. It is not known how many of those will finally become pregnant and have live births. Here, besides oncologic outcome, we extremely focused on their pregnancy outcome and pregnancy attempts.

\section{Patients and methods}

Medical records of EOC patients who had undergone fertility sparing surgery between January 2000 and December 2016 in Peking Union Medical College Hospital (PUMCH) were reviewed retrospectively. This study was approved by the ethics committee of PUMCH. All patients who received fertility sparing surgery were included. All patients received comprehensive surgical staging surgery, including unilateral salpingo-oophorectomy, a complete exploration of the whole peritoneum with multiple biopsies, washing cytology, omentectomy, bilateral pelvic lymph node dissection, and para-aortic lymph node dissection. Patients were staged according to the International Federation of Gynecology and Obstetrics criteria (FIGO, 2013) [6], using macroscopic findings and histological analysis of specimens obtained during staging surgery. Pathology slides were all reviewed by one pathologist in PUMCH. Histological cell type and tumor differentiation were assessed according to the World Health Organization (WHO) criteria [7]. Patients of non-epithelial ovarian cancer and borderline tumors were excluded.Clear cell carcinoma or stage IC plus disease was the indication of post-operative chemo-therapy. Most of patients after fertility sparing surgery received carboplatin/cisplatin based chemo-therapies. And all of the patients could be followed up every 3 months for the first 3 years, every 6 months for the next 2 years, then once in a year. Pregnancy and oncologic outcomes were evaluated.

\section{Results}

During January 2000 to December 2016, 40 patients of epithelial ovarian cancer supposed to early-stage received comprehensive fertility-sparing surgery at PUMCH. The baseline clinical data of all patients was shown in Table 1. All patients were low grade epithelial ovarian carcinoma. Median age at surgery was 28 years old (ranged from 18 to 44 years). 38 patients were early
Table 1 Clinical oncological data of all 40 patients of epithelial ovarian cancer

\begin{tabular}{|c|c|}
\hline & $\mathrm{N}(\%)$ \\
\hline Total & 40 \\
\hline Age at surgery, years Median (range) & 28 (18 44) \\
\hline Follow up, months Median (range) & $54(25 \sim 201)$ \\
\hline \multicolumn{2}{|l|}{ Histology } \\
\hline Serous & $4(10 \%)$ \\
\hline Mucinous & $19(47.5 \%)$ \\
\hline Endometriod & $8(20 \%)$ \\
\hline Clear cell & $10(22.5 \%)$ \\
\hline \multicolumn{2}{|l|}{ FIGO stage } \\
\hline $\mid A$ & $11(27.5 \%)$ \\
\hline IB & 0 \\
\hline IC & $27(67.5 \%)$ \\
\hline$\| A$ & 0 \\
\hline$\| B$ & $1(2.5 \%)$ \\
\hline$\| C$ & 0 \\
\hline IIIA & $1(2.5 \%)$ \\
\hline IIIB & 0 \\
\hline$\| I C$ & 0 \\
\hline \multicolumn{2}{|l|}{ Grading } \\
\hline Low & $40(100 \%)$ \\
\hline High & 0 \\
\hline \multicolumn{2}{|l|}{ Type of surgery } \\
\hline Laparoscopy & $16(40 \%)$ \\
\hline Laparotomy & $24(60 \%)$ \\
\hline \multicolumn{2}{|l|}{ Chemotherapy } \\
\hline Yes & $27(67.5 \%)$ \\
\hline No & $13(32.5 \%)$ \\
\hline \multicolumn{2}{|l|}{ Pregnancy plan } \\
\hline No & $27(67.5 \%)$ \\
\hline Yes & $13(32.5 \%)$ \\
\hline
\end{tabular}

stage (FIGO stage IA or IC) epithelial ovarian cancer. Two patients were upstaged after staging surgery according to FIGO criteria. One was stage IIB (laparoscopic staging surgery) and have disease recurrence after 5 months. The other was stage IIIA1 (laparotomy staging surgery) endometriod type with para-aortic lymph-node micro metastasis. She rejected additional TAH and USO, and received chemotherapy with paclitaxel and carboplatin for 6 cycles. No disease recurrence was found after following up 5 years. The tumor differentiations of all 40 patients were low grade. The mucinous type of tumor was the most common (47.5\%) histologic type. Then the next in sequence were clear cell (22.5\%), endometriod (20\%) and serous (10\%). $40 \%$ of patients were operated 
under laparoscopy. Most of patients (67.5\%) received chemo-therapy after surgery, including 5 stage IA patients who were all clear cell carcinoma. 7 patients with stage IC disease and 1 clear cell carcinoma with stage IA disease rejected post-operative chemo-therapy.

All patients were regularly followed up as described in Patients and Methods. Median follow up time was 54 months, with range of 25 201 months. The 2 year and 5 year of disease-free survival (DFS) were respectively 95 and $87.5 \% .16(40 \%)$ patients received laparoscopic staging surgery, and 2 (12.5\%) of them had relapse in 5 years. Meanwhile, 2 in 24 patients (8.3\%) who were done surgery through laparotomy relapsed. $67.5 \%$ patients received chemotherapy after primary staging surgery. 4 patients $(10 \%)$ had disease recurrences (Table 2). One patient was upgraded to IIB after laparoscopic comprehensive staging surgery and insisted sparing fertility. The histological type was mucinous and the patient received 4 cycles of paclitaxel plus carboplatin. Unfortunately tumor recurrence happened after 4 months. The rest 3 patients were all FIGO IC disease, with mucinous, clear cell and endometroid respectively. They all received at least 3 cycles chemotherapy after primary surgery. No death occurred.

Because of some private reasons, 27 patients (67.5\%) were single or contraceptive. 13 patients $(32.5 \%)$ desired to have a baby after treatment (Table 3). All of them were FIGO IA or IC epithelial ovarian cancer and had no disease recurrence during the whole follow-up period (range of 33 129 months) (Table 3). 5 patients (38.5\%) were infertility. Among them, 3 patients had chemotherapy with paclitaxel plus carboplatin, one with cyclophosphamide plus cisplatin, and the rest one patient didn't receive any chemotherapy. 8 patients $(61.5 \%)$ have successfully conceived spontaneously. All of them received common obstetric examination and regular oncologic follow up. Any radiographic test was avoided and CA125 was not regularly detected during pregnancy. The pregnancy outcomes have been shown in Table 4. 3 patients had fetus loss, including 1 natural abortion in the first trimester, 1 fetal anomaly (pregnancy was terminated at 23 weeks) and 1 fetus death (24 weeks) in uterus without exact reasons. 5 patients (38.5\%) had live births, including 2 premature births and 3 term births (Table 4).
There were no serious adverse in obstetric and neonatal outcomes among women with live births. No tumor recurrence happened during pregnancy.

\section{Discussion}

For young patients with early stage epithelial ovarian cancer, fertility-sparing surgery (FSS) is important. The first reports about FSS for EOC appeared in 1960s [8]. Then many case series undergoing FSS were reported. JCOG-FSS study and JCOG1203 study carried out by the Japan Clinical Oncology Group (JCOG) confirmed that FSS is safe for stage IA clear cell carcinoma (CCC) and IC non-CCC G1/G2 diseases [9, 10]. In 2011, Kajiyama reported that there were no any differences finding in oncologic outcome between radical surgery and FSS in stage I EOC patients. In FSS group, 52 patients $(86.7 \%)$ survived without relapse. There was no difference in disease free survival (DFS) and overall survival (OS) between stage IC (capsule rupture) and stage IA. The pregnancy rate was $15 \%(9 / 60)$. The authors suggested FSS can be safely proposed to all patients [11]. Many other retrospective analysis supported this conclusion [12, 13]. 2007 guidelines of American College of Obstetrics and Gynecology (ACOG) and 2008 guideline $\mathrm{s}$ of the European Society for Medical Oncology (ESMO), FSS was adopted for stage IA EOC patients and non-clear cell histology G1 and G2 [14, 15]. Limited data supported stage IB EOC patients or IC with bilateral ovarian disease preserving a part of the contralateral ovary. National comprehensive cancer network (NCCN) guideline version 2. 2018 of ovarian cancer suggested preserving the uterus only. In this retrospective study, 40 patients were all treated and regularly followed up in one tertiary hospital in Beijing, China. 5 years of DFS was $87.5 \%$ which is consistent with other reports. 4 patients relapsed but no death occurred. Based on above, for young EOC patients who desired to preserve fertility, FSS could be suggested in clinic. Besides, through a prospective study published in 2016, 6.1\% EOC patients were reclassified to a higher stage after laparoscopic fertility-sparing surgery. The overall survival of median follow-up period 38 months was $95.4 \%$ and recurrence-free survival $84.6 \%$ [16]. This work also showed $6.25 \%$ patients with laparoscopic staging surgery and $4.2 \%$ with laparotomy staging surgery were

Table 24 patients who developed recurrence

\begin{tabular}{lllllll}
\hline Pt & Age at surgery & FIGO stage & Histology, Grade & Type of surgery & Chemotherapy/cycles & DFS (months) \\
\hline 1 & 26 & IC & Mucinous, G1 & Laparotomy & Cyclophosphamide + Cisplatinum/5 & 144 \\
2 & 29 & IC & Endometriod, G1 & Laparotomy & Paclitaxel + Carboplatin/6 & 20 \\
3 & 40 & IC & Clear cell & Laparoscopy & Carboplatin/3 & 48 \\
4 & 33 & IIB & Mucinous, G1 & Laparoscopy & Paclitaxel + Carboplatin/4 & 4 \\
\hline
\end{tabular}

Pt: patients; DFS: disease free survival 
Table 3 Pregnancy outcomes of 13 patients

\begin{tabular}{ll}
\hline & $\mathrm{N}(\%)$ \\
\hline Age at surgery, years Median (range) & $27(18 \sim 40)$ \\
Histology & $1(7.7 \%)$ \\
Mucinous & $7(53.8 \%)$ \\
Endometriod & $3(23.1 \%)$ \\
Clear cell & $2(15.4 \%)$ \\
FIGO stage & \\
IA & $4(30.8 \%)$ \\
IC & $9(69.2 \%)$ \\
Chemotherapy & \\
Paclitaxel + Carboplatin & $8(61.5 \%)$ \\
Cyclophosphamide + Carboplatin & $1(7.7 \%)$ \\
Cyclophosphamide + Cisplatin & $2(15.4 \%)$ \\
No chemotherapy & $2(15.4 \%)$ \\
Pregnancy outcomes & \\
infertility & $5(38.5 \%)$ \\
Miscarriages & $3(23.0 \%)$ \\
Live birth & $5(38.5 \%)$ \\
Premature birth & 2 \\
\hline
\end{tabular}

upstaged. Laparoscopic staging surgery may a viable option for early stage EOC patients.

Except oncologic prognosis, pregnancy outcomes were also focused in this work. Marriage and reproduction of offspring are both not only individual behaviors but also social behaviors. 27 in 40 patients $(67.5 \%)$ who desired to preserve fertility at the beginning of cancer treatments were still single or have given up pregnancy intent. 5 in 13 patients who had baby plan had live births. The fertility rate was consistent with other published studies $[17,18]$. In 5 patients with live birth in this study, Platinum plus paclitaxel were used in 3 patients after surgery. 1 patient received 3 cycles of Cyclophosphamide plus carboplatin and delivered at 33 weeks because of premature rupture of fetal membranes. 1 patients was diagnosed with pregnancy only 1 month after the end of chemo-therapy and no neonatal malformation was found. All patients during pregnancy received common obstetric management and oncological follow-up. More appropriate medical managements for EOC patients after FSS and chemo-therapy during pregnancy has not been built up because of limited experience. There were no adequate evidence shown that platinum plus paclitaxel could lead to fetal mortality, abortion and neonatal malformation [19]. However, some other chemotherapeutic agents, such as alkylating, were proved poisonous to ovary which might result in premature ovarian failure and subsequent infertility [20].

This was a retrospective study in one tertiary hospital of China. Compared with multicenter research, the deviation and bias of data might be best eliminated. Nearly 18 years ago, fertility-staging surgery was gradually carried out in stage IA/IC low grade EOC patients who desired conserving fertility in Peking Union Medical College Hospital. All patients received complete staging surgery through laparoscopy or laparotomy. Chemotherapy was varied according to patients' conditions. And optimistic oncologic outcome was gained. Our experience supported us continuing this work for early stage EOC patients. The pregnancy outcomes for them was summarized for the first time. The rate of live birth was low but close to other published studies in the world. The sample was too small to analysis the high

Table 48 Patients with early epithelial ovarian cancer who were pregnancy after staging surgery

\begin{tabular}{|c|c|c|c|c|c|c|c|}
\hline $\mathrm{Pt}$ & $\begin{array}{l}\text { Age at } \\
\text { surgery }\end{array}$ & $\begin{array}{l}\mathrm{FIGO} \\
\text { stage }\end{array}$ & $\begin{array}{l}\text { Histology, } \\
\text { Grade }\end{array}$ & $\begin{array}{l}\text { Type of } \\
\text { surgery }\end{array}$ & Chemotherapy /cycles & ${ }^{*}$ Interval & Pregnancy outcome \\
\hline 1 & 27 & $\mid A$ & $\begin{array}{l}\text { Endometriod, } \\
\text { G1 }\end{array}$ & Laparotomy & Paclitaxel + Carboplatin/7 & 36 & Miscarriage during 1st trimester \\
\hline 2 & 30 & $\mathrm{IC}$ & Mucinous, G1 & Laparotomy & $\begin{array}{l}\text { Cyclophosphamide + } \\
\text { Carboplatin/3 }\end{array}$ & 24 & Dead fetus in uterus at 24 weeks \\
\hline 3 & 30 & $\mathrm{IC}$ & Mucinous, G1 & Laparotomy & Paclitaxel + Carboplatin/7 & 22 & Fetal anomaly at 23 weeks \\
\hline 4 & 28 & $\mid A$ & Mucinous, G1 & Laparoscopy & $\begin{array}{l}\text { Cyclophosphamide }+ \\
\text { Cisplatin/3 }\end{array}$ & 12 & Vaginal delivery at 33 weeks because of PROM \\
\hline 5 & 33 & IC & Mucinous, G1 & Laparotomy & Paclitaxel + Carboplatin/6 & 36 & Vaginal delivery at 38 weeks \\
\hline 6 & 30 & $\mid A$ & Clear cell & Laparotomy & No chemotherapy & 12 & Vaginal delivery at 39 weeks \\
\hline 7 & 27 & $\mathrm{IC}$ & Serous, G1 & Laparoscopy & Paclitaxel + Carboplatin/5 & 1 & Cesarean section at 37 weeks \\
\hline 8 & 26 & $\mathrm{IC}$ & Mucinous, G1 & Laparotomy & Paclitaxel + Carboplatin/6 & 60 & $\begin{array}{l}\text { Vaginal delivery at } 36 \text { weeks because of } \\
\text { spontaneous labor }\end{array}$ \\
\hline
\end{tabular}

Pt: patients; ${ }^{*}$ interval: the interval between terminal of chemotherapy with pregnancy diagnosed; PROM: premature rupture of membranes 
risk factors of infertility and abnormal pregnancy. And the follow-up time was so short for some absolutely young patients who have not been married yet. The pregnancy rate might be improved if the following-up could be continued.

\section{Abbreviations}

BSO: Bilateral salpingo-oophorectomy; CCC: Clear cell carcinoma;

DFS: Disease free survival; EOC: Epithelial ovarian cancer; FSS: Fertility sparing surgery; OS: Overall survival; TAH: Total abdominal hysterectomy;

USO: Unilateral salpingo-oophorectomy

\section{Acknowledgments}

We thank all of the patients for receiving our following-up in the study.

\section{Funding}

None.

\section{Availability of data and materials}

The datasets used and/or analyzed during the current study are available from the corresponding author on reasonable request.

\section{Authors' contributions}

JY, Project development, data collection, and manuscript writing; YW and YS, Data collection; YL and YJ, Data analysis and manuscript editing; LP, Project development and manuscript editing. All authors read and approved the final manuscript.

\section{Ethics approval and consent to participate}

The study was approved by the ethics committee of Peking Union Medical College Hospital.

\section{Competing interests}

The authors declare that they have no competing interests.

\section{Publisher's Note}

Springer Nature remains neutral with regard to jurisdictional claims in published maps and institutional affiliations.

Received: 4 December 2018 Accepted: 3 May 2019

Published online: 14 May 2019

\section{References}

1. Heintz AP, Odicino F, Maisonneuve P, et al. Carcinoma of the ovary. Int J Gynaecol Obstet. 2003;83(Suppl 1):135-66

2. Schlaerth AC, Chi DS, Poynor EA, Barakat RR, Brown CL. Long-term survival after fertility-sparing surgery for epithelial ovarian cancer. Int J Gynecol Cancer. 2009;19:1199-204.

3. Schilder JM, Thompson AM, DePriest PD, et al. Outcome of reproductive age women with stage IA or IC invasive epithelial ovarian cancer treated with fertility-sparing therapy. Gynecol Oncol. 2002;87:1-7.

4. Wright JD, Shah M, Mathew L, et al. Fertility preservation in young women with epithelial ovarian cancer. Cancer. 2009;115:4118-26.

5. Melamed A, Rizzo AE, Nitecki R, et al. All-cause mortality after fertilitysparing surgery for stage I epithelial ovarian Cancer. Obstet Gynecol. 2017;130:71-9

6. Prat J, Oncology FCoG. Staging classification for cancer of the ovary, fallopian tube, and peritoneum. Int J Gynaecol Obstet. 2014;124:1-5.

7. Kurman RJ. International Agency for Research on Cancer, World Health Organization. WHO classification of tumours of female reproductive organs. 4th ed. Lyon: International Agency for Research on Cancer; 2014.

8. Munnell EW. Is conservative therapy ever justified in stage I (IA) cancer of the ovary? Am J Obstet Gynecol. 1969;103:641-53.

9. Fruscio R, Corso S, Ceppi L, et al. Conservative management of early-stage epithelial ovarian cancer: results of a large retrospective series. Ann Oncol. 2013;24:138-44.

10. Satoh T, Tsuda H, Kanato K, et al. A non-randomized confirmatory study regarding selection of fertility-sparing surgery for patients with epithelial ovarian cancer: Japan clinical oncology group study (JCOG1203). Jpn J Clin Oncol. 2015:45:595-9.

11. Kajiyama H, Shibata K, Suzuki S, et al. Fertility-sparing surgery in young women with invasive epithelial ovarian cancer. Eur J Surg Oncol. 2010;36:404-8

12. Ditto A, Martinelli F, Bogani $G$, et al. Long-term safety of fertility sparing surgery in early stage ovarian cancer: comparison to standard radical surgical procedures. Gynecol Oncol. 2015;138:78-82.

13. Fruscio $R$, Ceppi L, Corso $S$, et al. Long-term results of fertility-sparing treatment compared with standard radical surgery for early-stage epithelial ovarian cancer. Br J Cancer. 2016;115:641-8.

14. American College of O, Gynecologists. ACOG Practice Bulletin. Management of adnexal masses. Obstet Gynecol. 2007;110:201-14.

15. Aebi S, Castiglione M, Group EGW. Epithelial ovarian carcinoma: ESMO clinical recommendations for diagnosis, treatment and follow-up. Ann Oncol. 2008;19(Suppl 2):ii14-6.

16. Ghezzi F, Cromi A, Fanfani F, et al. Laparoscopic fertility-sparing surgery for early ovarian epithelial cancer: a multi-institutional experience. Gynecol Oncol. 2016;141:461-5.

17. Ditto A, Martinelli F, Lorusso D, Haeusler E, Carcangiu M, Raspagliesi F. Fertility sparing surgery in early stage epithelial ovarian cancer. J Gynecol Oncol. 2014;25:320-7.

18. Ratanasrithong P, Benjapibal M. Pregnancy outcomes after conservative surgery for early-stage ovarian neoplasms. Asian Pac J Cancer Prev. 2017;18:2083-7.

19. Zheng $X$, Zhu $Y$, Zhao $Y$, Feng $S$, Zheng $C$. Taxanes in combination with platinum derivatives for the treatment of ovarian cancer during pregnancy: a literature review. Int I Clin Pharmacol Ther. 2017;55:753-60.

20. Byrne J, Fears TR, Gail MH, et al. Early menopause in long-term survivors of cancer during adolescence. Am J Obstet Gynecol. 1992;166:788-93.

\section{Ready to submit your research? Choose BMC and benefit from:}

- fast, convenient online submission

- thorough peer review by experienced researchers in your field

- rapid publication on acceptance

- support for research data, including large and complex data types

- gold Open Access which fosters wider collaboration and increased citations

- maximum visibility for your research: over $100 \mathrm{M}$ website views per year

At BMC, research is always in progress.

Learn more biomedcentral.com/submissions 